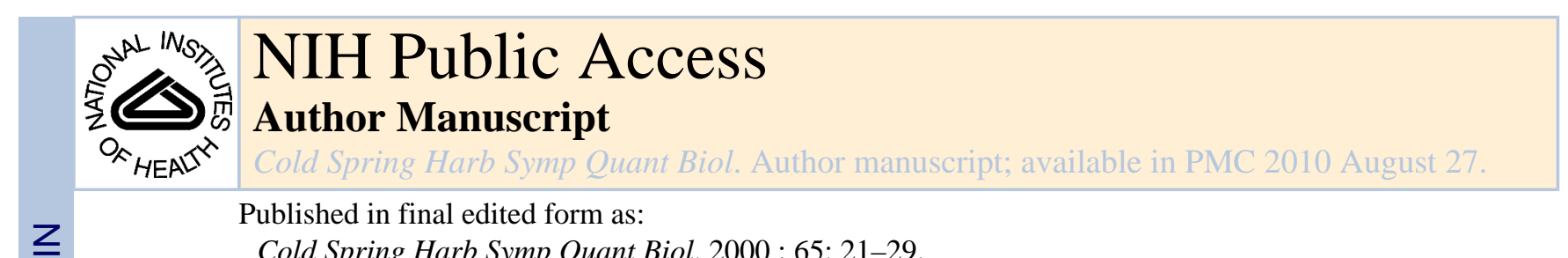

Published in final edited form as:

Cold Spring Harb Symp Quant Biol. 2000 ; 65: 21-29.

\title{
Adaptive Mutation in Escherichia coli
}

\author{
P.L. Foster \\ Department of Biology, Jordan Hall 142, Indiana University, Bloomington, Indiana 47405-6801
}

We usually think of spontaneous mutations as the result of replication errors made while cells are growing exponentially. That mutations do arise during cell proliferation and without regard to selection was, of course, shown by Luria and Delbrück (1943). Several years ago, John Cairns and his collaborators (Cairns et al. 1988) demonstrated that mutations can also arise in nonproliferating cells when they are subjected to a nonlethal selection. These experiments extended earlier observations made by Francis Ryan (Ryan 1955; Ryan et al. 1961) and James Shapiro (Shapiro 1984).

Luria and Delbrück's proof that mutations arise at random in a growing population was based on large fluctuations in mutant numbers among parallel cultures of bacteria. These large fluctuations occur because clones of different sizes are produced by mutants that appear at different points during the growth of the cultures. Cairns et al. (1988) used the absence of large fluctuations in mutant numbers among parallel cultures to demonstrate that mutations also arise after selection had been imposed. Because on solid selective medium each mutant produces a colony of progeny cells, and so is counted as one, the distribution of mutant numbers is Poisson with a variation equal to its mean. Luria and Delbrück could not have seen this Poisson component; the selections they used were lethal, so no mutants could have arisen after selection was imposed, as Delbrück himself pointed out at the 1946 Cold Spring Harbor Symposium (see Lwoff 1946, p. 154).

Although the occurrence of mutations in nonproliferating cells is an interesting and potentially important phenomenon, what was startling about the results of Cairns et al. (1988) was that mutations appeared to be "directed" by the selective conditions; i.e., while selected mutations were accumulating, deleterious or neutral mutations were not. As Cairns put it "populations of bacteria, in stationary phase, have some way of producing (or selectively retaining) only the most appropriate mutations" (Cairns et al. 1988). Some of the more dramatic cases of "directed" mutation have now been shown to have other causes, so at this point we are left with rather few examples of apparent directedness that are still unexplained (for review, see Foster 1999b). The phenomenon has come to be called "adaptive mutation" by which is meant a process that during nonlethal selection produces mutations that relieve the selected pressure, whether or not other nonselected mutations are also occurring (Foster 1999b).

Work in my laboratory has focused on a strain of Escherichia coli, FC40, that cannot utilize lactose $\left(\mathrm{Lac}^{-}\right)$but that readily reverts to lactose utilization $\left(\mathrm{Lac}^{+}\right)$when plated on medium with lactose as the sole carbon and energy source (Cairns and Foster 1991). These $\mathrm{Lac}^{+}$mutations are not "directed" in the original sense because non-selected mutations in another gene closely linked to lac also accumulate in the $\mathrm{Lac}^{-}$population during lactose selection (Foster 1997). Nonetheless, research on FC40 has provided insights into mechanisms by which mutations can occur in nonproliferating cells. In the first part of this paper, I review the characteristics of adaptive $\mathrm{Lac}^{+}$mutation in FC40 and present a model for how the mutations are produced. Included are new data indicating that three of $E$. coli's DNA polymerases are active in this process. In the second part of the paper, I focus on the occurrence of transient mutators in populations of cells under selection and discuss possible mechanisms by which mutation rates can be temporarily increased. 


\section{THE SPECTRUM OF ADAPTIVE LAC+ MUTATIONS}

When E. coli strain FC40 is incubated on lactose plates, $\mathrm{Lac}^{+}$colonies arise at a constant rate for about 1 week. During this period, the number of $\mathrm{Lac}^{-}$cells does not detectably change (Cairns and Foster 1991; Foster 1994). FC40 is deleted for the lac operon on its chromosome but carries a revertible $\mathrm{lac}^{-}$allele on the conjugal plasmid, $\mathrm{F}$. The allele is a fusion of the lacI gene to the lacZ gene (Müller-Hill and Kania 1974) with a +1 frameshift mutation induced by ICR191 in the lacI sequence (Calos and Miller 1981; Miller 1985). Because the amino acid sequence of the LacI part of the fusion is irrelevant, the allele can be reverted to $\mathrm{Lac}^{+}$by any mutation within a 130-bp region that restores the frame without creating a nonsense codon. The mutations that occur during exponential growth consist of all types, including -1-bp deletions and also larger deletions, duplications, and rearrangements. In contrast, the mutations that give rise to the late-arising colonies (the "adaptive" mutations) are almost exclusively simple -1-bp deletions. Most of these occur at runs of G:C base pairs, and greater than 50\% occur at one hot spot, which is the site of the original +1 frameshift (Foster and Trimarchi 1994; Rosenberg et al. 1994; Foster et al. 1995).

This spectrum of adaptive $\mathrm{Lac}^{+}$mutations - simple frameshift mutations in runs of iterated bases-is typical of polymerase errors. Such events become dominant when polymerases lack editing functions or when postreplication mismatch repair functions are not operating. The interesting questions are then: (1) What initiates DNA synthesis in nonproliferating cells? (2) Which DNA polymerases are responsible for the mutations?

\section{RECOMBINATION-DEPENDENT MUTATION}

The genetic requirements for mutation to $\mathrm{Lac}^{+}$during lactose selection in $\mathrm{FC} 40$, given in Table 1 , distinguish the process from mutation to $\mathrm{Lac}^{+}$during nonselected growth. Adaptive mutation, but not growth-dependent mutation, requires recombination functions, in particular the RecABCD pathway for double-strand break repair (Cairns and Foster 1991;Foster 1993; Harris et al. 1994;Foster and Rosche 1999). E. coli has two enzyme systems that translocate recombination intermediates, RuvAB and RecG; although both of these systems contribute to normal recombination, adaptive mutation is severely reduced in $r u v A B^{-}$mutant cells but 100-fold enhanced in $r e c G^{-}$mutant cells (Foster et al. 1996; Harris et al. 1996). LexA, the repressor of the SOS regulon in E. coli, represses both recA and the ruvAB operon. Adaptive mutation in FC40 is severely inhibited in a strain carrying an allele of lexA that prevents SOS induction, lexA $\left(\mathrm{Ind}^{-}\right.$) (Cairns and Foster 1991;McKenzie et al. 2000). We found that this inhibition is partially relieved by constitutive expression of RecA (Foster et al. 1996) but not relieved by supplying $r u v A B^{+}$on a low-copy plasmid (P.L. Foster, unpubl.). Therefore, expression of at least one LexA-repressed gene, in addition to $r e c A$ and $r u v A$, is required for the maximal rate of adaptive mutation. As discussed below, this gene is likely to be $\operatorname{din} B$.

It has long been known that recombination intermediates prime DNA replication in phage T4 (Mosig 1998) but that recombination and replication are usually coupled has only recently been recognized. Although other pathways exist (McGlynn and Lloyd 2000), double-strand break repair may be an important way by which stalled or broken replication forks are restarted during normal replication (Cox et al. 2000). Double-strand breaks can be created when a replication fork encounters a nick or if a fork stalls and the two newly synthesized strands anneal (Kuzminov 1995; Seigneur et al. 1998). It is assumed that RecA-catalyzed invasion of a single strand into an homologous duplex primes DNA synthesis (Kuzminov 1995; Kogoma 1997b), although direct evidence for this has only recently been obtained (Kuzminov and Stahl 1999). priA encodes a protein normally required to assemble the $\varphi$ X174 primosome, and cells with null mutations in priA are partially defective for homologous recombination. This result implies that at least some forms of recombination require de novo DNA synthesis and that the PriA- 
primosome initiates this synthesis (Kogoma et al. 1996; Sandler et al. 1996). The poor viability of recA and priA mutant cells indicates how important these functions are during normal growth (for recent reviews, see Kuzminov 1999; Cox et al. 2000; Kowalczykowski 2000).

In addition to recombination functions, the high rate of adaptive mutation requires that the lac allele be on the $\mathrm{F}$ episome and that conjugal functions be expressed (Foster and Trimarchi 1995a; Galitski and Roth 1995; Radicella et al. 1995); however, actual conjugation is not required (Foster and Trimarchi 1995a,b). When the lac allele is on the chromosome, the rate of adaptive mutation falls 100-fold (Foster and Trimarchi 1995a; Radicella et al. 1995), and the mutations are no longer dependent on recombination functions (Foster and Trimarchi 1995a). During conjugation, a nick at the episome's conjugal origin, oriT, initiates transfer of the donor DNA to the recipient. However, nicking occurs even in the absence of a mating signal and persists in stationary-phase cells (Firth et al. 1996; Frost and Manchak 1998). Homologous recombination between the episome and the chromosome is stimulated 20-50-fold by nicking at $o r i T$, and this enhanced recombination is dependent on RecABCD (Seifert and Porter 1984; Carter and Porter 1991; Carter et al. 1992). All of these facts can be assembled into the following model for recombination-dependent mutation in FC40 (Kuzminov 1995; Foster et al. 1996).

When FC40 is incubating on lactose, the cells are not proliferating, but occasionally, replication is initiated at one of the episome's vegetative origins, oriS or oriV (Fig. 1a; only DNA replication initiated at the unidirectional origin, oriS, is illustrated). Because nicking at oriT is persistent, the replication fork will have a high probability of encountering the nick, at which point it will collapse, creating a double-strand end (Fig. 1b). (In the intermolecular reaction shown in Figure 1, synthesis of the unbroken strand continues until the strand is ligated to the 5 ' end of the nick; this would require removal of the covalently attached TraI protein; Fig. 1c.) The double-stranded end of the collapsed replication fork is recognized by the RecBCD enzyme, which initiates double-strand break repair by degrading the $5^{\prime}$ strand, producing an invasive 3' single strand (Fig 1d; the DNA segment is flipped vertically for clarity). After RecAcatalyzed invasion of the single strand into the homologous duplex of the sister chromosome (Fig. 1e) or another episome, new DNA synthesis is primed, requiring the actions of DNA polymerase IV, II, and III and the PriA-primosome (see below). It is at this point, as the new synthesis copies the lac region, that the polymerase errors that give rise to the $\mathrm{Lac}^{+}$mutations are made. Eventually, a new replication fork is established (Fig. 1f), but the four-stranded recombination intermediate (a Holliday junction) remains. The Holliday junction is resolved by RuvAB-catalyzed branch migration and RuvC-catalyzed strand cleavage, or by RecGcatalyzed branch migration and resolution via an unknown mechanism (Fig. 1g).

\section{ADDITIONAL ROLES OF RuvAB AND RecG IN Lac+ ADAPTIVE MUTATION}

As mentioned above, adaptive $\mathrm{Lac}^{+}$mutations are enhanced about 100 -fold in $\mathrm{rec} G^{-}$mutant cells, implying that RecG normally prevents mutations (Foster et al. 1996; Harris et al. 1996). Understanding the meaning of this result has been hampered by the lack of understanding what RecG really does in vivo (for a recent review, see Kuzminov 1999). Like RuvAB, the RecG enzyme is a junction-specific helicase. However, in vitro in the presence of RecA, RecG and RuvAB catalyze branch migration in opposite directions, direction being defined by the $5^{\prime}$ to $3^{\prime}$ polarity of RecA polymerization (Whitby et al. 1993). If this polarity obtains in vivo, then the Holliday junction shown in Figure 1f would be translocated toward the fork by RuvAB and away from the fork by RecG. As shown in Figure 1g, translocation toward the fork would result in the pairing of two newly synthesized strands of DNA. In $E$. coli, newly synthesized DNA is not immediately methylated, and the transient state of hemimethylation allows the mismatch repair system to correct a mismatch in favor of the methylated template strand (Modrich and Lahue 1996). Thus, if RuvAB-catalyzed branch 
migration produces paired unmethylated strands, any mismatches produced by the new synthesis would be corrected at random, preserving as many errors as are corrected. By translocating the Holliday junction in the opposite direction, RecG would oppose this process, reducing the number of $\mathrm{Lac}^{+}$mutations (Foster et al. 1996).

RecG is also known to resolve Holliday junctions in conjunction with nucleases other than RuvC (Mandal et al. 1993) and to interact and translocate three-stranded intermediates (Dloops) (Whitby and Lloyd 1995). If RecG resolves the Holliday junction before DNA synthesis is initiated, or aborts the recombination event at the three-stranded stage, fewer mutations would result (Foster et al. 1996; Harris et al. 1996). Yet another possibility is discussed below.

\section{THE DNA POLYMERASES INVOLVED IN Lac ${ }^{+}$ADAPTIVE MUTATION}

E. coli's known polymerases and their characteristics are listed in Table 2. In the last year, two previously unknown DNA polymerases have been discovered. pol IV, encoded by $\operatorname{din} B$, and pol $\mathrm{V}$, encoded by $и т и C$, are low-fidelity polymerases with poor processivity and no proofreading functions (Tang et al. 1999; Wagner et al. 1999). In E. coli, these polymerases are repressed by LexA and induced by DNA damage. pol $\mathrm{V}$ is responsible for translesion bypass of UV-damaged bases and tends to make base substitution mutations on undamaged DNA (Tang et al. 2000). The cellular role of pol IV is less obvious, but it has the ability to extend DNA synthesis from a misaligned terminus and tends to make frameshift mutations (Kim et al. 1997; Wagner et al. 1999). pol II is also repressed by LexA, but it is an accurate, processive polymerase that may be responsible for restarting replication after UV irradiation (Rangarajan et al. 2000).

We have examined all of these polymerases for their roles in $\mathrm{Lac}^{+}$adaptive mutation in $\mathrm{FC} 40$. A polymerase-defective allele of pol I, polAl, increases adaptive mutation (P.L. Foster, unpubl.). Loss of pol I causes induction of the SOS response (Bates et al. 1989), so this result probably means only that some other gene is being induced (see below). The polymerase activity of pol III, the replicative polymerase, is essential, and so its role must be inferred from the phenotypes of non-null mutations. The polymerase subunit of pol III, $\alpha$, is encoded by the $d n a E$ gene. An allele of $d n a E$, dnaE915, that confers an antimutator phenotype (Fijalkowska and Schaaper 1993) decreases adaptive mutation about threefold (Fig. 2) (Foster et al. 1995;

Harris et al. 1997). Adaptive mutation is enhanced in $\Delta$ (polB) mutant cells (Fig. 2) (Escarceller et al. 1994) and the resulting extra mutations are also reduced by dnaE915 (Fig. 2) (Foster et al. 1995). We originally took this result to mean that both pol II and pol III were active during lactose selection, but that pol III was responsible for the $\mathrm{Lac}^{+}$mutations. However, new results have suggested another interpretation.

As mentioned above, at least one unknown LexA-repressed protein is required for the maximal rate of adaptive mutation in FC40. This protein is not pol V, at least in wild-type cells (Cairns and Foster 1991; McKenzie et al. 2000), but it may be pol IV. Loss of pol IV causes a twofold reduction in adaptive mutation (Fig. 2) (E. Ohashi and H. Ohmori, pers. comm.). Although this result means that pol IV is not required for adaptive mutation (Foster 1999b), it most likely means that pol IV is responsible for half of the mutations. The magnitude of this effect is consistent with pol IV being the missing LexA-repressed protein.

To further study the role of pol IV in adaptive mutation, I combined a null allele of $\operatorname{din} B$ ( $\triangle$ dinB::Kan from strain YG7202; Kim et al. 1997) with alleles of pol II and pol III. In FC40, $\operatorname{din} B$ is on the episome and on the chromosome, so both copies were made $\triangle \operatorname{din} B::$ Kan. Shown in Figure 2 is the mean ( \pm SEM) number of $\mathrm{Lac}^{+}$colonies arising from day 3 to day 5 after plating on lactose medium; these late-arising $\mathrm{Lac}^{+}$mutants are due to adaptive mutations. Several experiments have been combined, and each value represents from 12 to 23 determinations using our small-scale assay (described in Foster et al. 1996). As we previously 
reported (Escarceller et al. 1994), eliminating pol II with a $\Delta($ polB $)$ mutation increases adaptive mutation about threefold. But, although loss of pol IV $(\Delta[\operatorname{din} B])$ has only about a twofold effect in otherwise wild-type cells, the increase in mutations due to $\Delta(\mathrm{pol} B)$ is completely eliminated if the cells are both $\Delta(\operatorname{pol} B)$ and $\Delta(\operatorname{din} B)$. This result suggests that the extra mutations are due to pol IV; to put it another way, pol II normally limits pol IV to about $20 \%$ of its mutagenic potential.

As shown in Figure 2, the antimutator dnaE915 allele reduces adaptive $\mathrm{Lac}^{+}$mutation in all backgrounds to nearly equal levels. There are some residual extra mutations in dnaE915 $\Delta$ ( polB ) mutant cells, which are eliminated if the cells are also $\Delta(\operatorname{din} B)$. The simplest explanation for this result is that the dnaE915 allele is better at preventing the mutagenic activity of pol IV than is $d n a E^{+}$. Furthermore, I suggest that $d n a E 915$ is an antimutator because it limits the access of less accurate polymerases to the DNA template. The residual mutations in $\Delta($ polB $)$ $\Delta(\operatorname{din} B)$ cells, missing both pol II and pol IV, could be due to pol III, in which case the dnaE915 allele would also improve the accuracy of pol III. However, these residual mutations could also be due to pol $\mathrm{V}$, whose mutagenic activity at this low level would be undetectable in wild-type cells.

These results can be readily assimilated into the model presented above (see Fig. 1), drawing upon the models for translesion synthesis and replication restart recently developed (see Goodman 2000). The reinitiation of replication by recombination requires that the replication fork be reestablished in the absence of the normal origin, oriC. It is probably the role of the PriA-primosome to do this, and the polymerase that it initially uses is pol II. This complex then gives way to the normal replication complex containing pol III, which completes the round of replication. Occasionally, pol IV gains access to the terminus and is able to do some errorprone synthesis before pol III takes over, and this accounts for $50 \%$ of the mutations observed. Most of the other $50 \%$ are likely to be due to pol III, although the involvement of another unknown polymerase is not ruled out. pol $\mathrm{V}$ can also participate in these events, but because it does not make frameshift mutations, its presence is usually not detected using the lac allele in FC40.

In support of this model, a null mutation of priA completely inhibits adaptive mutation in FC40 (P.L. Foster, unpubl.). In addition, the SOS response is partially derepressed in $r e c G$ mutant cells (Lloyd and Buckman 1991), so the increase in adaptive mutation seen in the absence of RecG could be due to higher than normal levels of pol IV. Also supporting this model is the finding that adaptive mutation in FC40 is reduced about twofold in recF mutant cells (McKenzie et al. 2000; P.L. Foster, unpubl.). RecF, together with RecO and RecR, helps RecA to polymerize on single-stranded DNA when it is coated with single-stranded binding protein (SSB); in this role, Rec-FOR participates in a variety of recombinational processes, including restarting replication after DNA damage (for review, see Kuzminov 1999). recF and lexA $\left(\mathrm{Ind}^{-}\right)$mutations are epistatic for adaptive mutation (McKenzie et al. 2000), which means only that RecF participates in the same pathway as one or more LexA-repressed genes. Since pol IV, but not RecF, is repressed by LexA, an attractive hypothesis is that RecF (plus RecO and RecR) facilitates the entry of pol IV into the recombination intermediate. It has previously been suggested that these proteins interact with the replication complex (Kogoma 1997a; Kuzminov 1999), and it is not unreasonable that they may participate in deciding which polymerase begins synthesis.

\section{TRANSIENT MUTATION}

A number of interesting hypotheses were proposed to explain the "directedness" of mutations described by Cairns et al. (1988). Most involve some form of "trial and error" by which a variant could be tested for its usefulness before being immortalized as a mutation (Cairns et 
al. 1988; Stahl 1988). The most extreme of these is the hypermutable state model (Hall 1990). Hall proposed that during nonlethal selection, a subpopulation of cells would have a greatly increased mutation rate and sustain mutations throughout their genomes. If a cell achieved a mutation that allowed it to begin to divide, it would exit this state, recovering its normal mutation rate. But, if no useful mutation occurred, the hypermutating cells would die. This process would achieve the appearance of "directedness" in the population because the cells that bore only useless or deleterious mutations would be eliminated. Thus, the trial and error would be conducted at the cellular level, instead of the molecular level.

All of the trial and error models predict that successful cells, i.e., those that have a selected mutation, should be burdened with extra, nonselected mutations at a higher than expected frequency (Foster 1993). This prediction is perhaps stronger for the hypermutable state model than for the others. Hall looked for the occurrence of nonselected mutations among successful mutants and found them at about a 20 -fold higher frequency than among the population at large (Hall 1990). Similar results were obtained by Boe (1990) and recently by three groups working with strain FC40 (Foster 1997; Torkelson et al. 1997; Rosche and Foster 1999; Godoy et al. 2000). When tested, the majority of the cells carrying extra mutations are not mutators (Torkelson et al. 1997; Rosche and Foster 1999; Godoy et al. 2000), indicating that the mutational state is transient.

In 1991, Jacques Ninio wrote a perspicacious article modeling contributions to spontaneous mutations that are made by stable mutators (i.e., cells that have a genetic defect that increases their mutation rate) and "transient mutators" (i.e., cells that do not have a genetic defect, but display a mutator phenotype; Ninio 1991). Ninio hypothesized that transient mutators would be cells defective in correcting their replication errors because they failed to inherit the requisite number of repair proteins or because their replication or repair proteins were faulty due to transcriptional or translational errors. He concluded that transient mutators contribute far more to mutations arising in a population than do stable mutators but that their contribution to any single type of mutation is nonetheless minor.

More recently, Cairns (1998) produced a simple model which assumes that the population contains only two types of cells, high mutators that are a small proportion (p) of the population and normal low mutators that make up the rest (1-p). High mutators have an M-fold higher mutation rate for all types of mutations than do low mutators. The contribution to any class of mutation made by each of these two subpopulations can be formulated in terms of the two unknowns, $\mathrm{p}$ and $\mathrm{M}$, with a minimum of assumptions (mainly, that $\mathrm{p} \ll 1$ and that $\mathrm{p}$ and $\mathrm{M}$ remain substantially the same during the course of an experiment) (Cairns 1999).

To determine how important transient mutators are to adaptive $\mathrm{Lac}^{+}$mutation in strain FC40, we put values on $\mathrm{p}$ and M (Rosche and Foster 1999). To do this, we chose a broad mutational screen, loss of motility. Mutations in more than 50 genes affect motility, so this one phenotypic screen samples about $1 \%$ of the genome for defects. We obtained two independent measurements: $\mathrm{R}_{1 / 0}$, the factor by which motility defects are more frequent among $\mathrm{Lac}^{+}$ revertants than among $\mathrm{Lac}^{-}$cells, and, $\mathrm{R}_{2 / 0}$, the factor by which motility defects are more frequent among $\mathrm{Lac}^{+}$revertants bearing one other mutation than among $\mathrm{Lac}^{-}$cells.

We found that $\mathrm{R}_{1 / 0}=24$; i.e., motility defects were about 20 -fold more frequent in the selected $\mathrm{Lac}^{+}$cells than among the population as a whole (Rosche and Foster 1999). This result is of the same magnitude as that obtained by Hall (1990), Boe (1990), and Torkelson et al. (1997). We found that $\mathrm{R}_{2 / 0}=203$; i.e., motility defects were about 200 -fold more frequent in the selected $\mathrm{Lac}^{+}$cells that also carried another mutation than among the population as a whole. A very similar value of 183 can be calculated from the data of Torkelson et al. (1997). From these values for $\mathrm{R}_{1 / 0}$ and $\mathrm{R}_{2 / 0}$, $\mathrm{p}$ and $\mathrm{M}$ were calculated to be $5.7 \times 10^{-4}$ and 231, i.e., about 
$0.1 \%$ of the cells in the population under selection are transient mutators, and their mutation rate is raised about 200-fold. From these numbers, the proportion of single mutants that arise from the transient mutators can be calculated to be 0.12 , i.e., only about $10 \%$ of the adaptive $\mathrm{Lac}^{+}$mutants (or any other class of single mutant) are arising in the transient mutators. In contrast, $97 \%$ of the double mutants come from the transient mutators. These numbers are remarkably similar to those Ninio derived from theoretical considerations (Ninio 1991).

The conclusion from our calculations is that most $\mathrm{Lac}^{+}$adaptive mutations arise in the normal population, not in the subpopulation of transient mutators. This was not Hall's original hypothesis (Hall 1990), nor what other workers believe (Torkelson et al. 1997), so it is worthwhile to derive the same result without models. We found that $210 / 3168(=6.6 \%)$ of the $\mathrm{Lac}^{+}$cells had motility defects, but 8/13 $(=61.5 \%)$ of the $\mathrm{Lac}^{+}$cells with another mutation had motility defects. Therefore, the population producing double mutants (the transient mutators) has a 10-fold higher rate of mutations giving motility defects than the population producing single mutants. Thus, most single mutants do not arise from the transient mutators; if we assume there are only two types of cells, then most of the $\mathrm{Lac}^{+}$mutants must arise from normal cells. However, the transient mutators do give rise to nearly all cells with two or more mutations.

Our results differ in another way from Hall's original hypothesis. We found that the proportion of $\mathrm{Lac}^{+}$clones with a motility defect increased linearly with time, meaning that the transient mutators did not die during the 5 days of our experiments (Rosche and Foster 1999). This result has been recently confirmed (Godoy et al. 2000).

We measured the accumulation of motility defects among $\mathrm{Lac}^{+}$revertants in two other strains (Rosche and Foster 1999). The first strain carries the revertible lac allele on its chromosome and has no episome. Although the mutation rate to $\mathrm{Lac}^{+}$during lactose selection is 100 -fold lower in this strain than when the lac allele is on the episome, the frequency of motility defects among the $\mathrm{Lac}^{+}$revertants was not significantly altered. Thus, the episome is not required to produce the transient mutator state. The second strain has the lac allele on the episome, but is defective in methyl-directed mismatch repair. In this strain, the frequency of motility defects among the $\mathrm{Lac}^{+}$revertants was not changed, but the frequency of motility defects among $\mathrm{Lac}^{-}$cells was elevated to the level found among $\mathrm{Lac}^{+}$revertants; i.e., the mutation rate of the $\mathrm{Lac}^{-}$population was increased by the loss of mismatch repair, but the mutation rate of the transient mutators was not. This means that mismatch repair is not operative in the transient mutators.

Levels of methyl-directed mismatch repair proteins decline in stationary-phase cells (Feng et al. 1996), although the mismatch repair activity that remains is sufficient to repair $90 \%$ of the errors that could lead to adaptive $\mathrm{Lac}^{+}$mutations (Foster and Cairns 1992; Reddy and Gowrishankar 1997; Foster 1999a). Yet, with fewer proteins, the repair capacity of nutritionally deprived cells might be easily saturated. Adaptive mutation to $\mathrm{Lac}^{+}$is enhanced in $\mathrm{recD}^{-}$and rec $G^{-}$mutant cells (Harris et al. 1994, 1996; Foster et al. 1996: Foster and Rosche 1999); the frequencies of second mutations among $\mathrm{Lac}^{+}$adaptive mutants are also increased by these two genetic defects (Foster 1997; Bull et al. 2000). As mentioned above, the SOS response is partially induced in rec $G$ mutant cells (Lloyd and Buckman 1991). In recD mutant cells, the exonuclease activity of the RecBC enzyme is eliminated but the helicase activity remains, resulting in the production of an excess of single-stranded DNA that also enhances SOS induction (Chaudhury and Smith 1985; Rinken et al. 1992). About 0.1\% of stationary-phase cells of FC40 are filamentous, a symptom of SOS induction (W.A. Rosche and P.L. Foster, unpubl.). I previously hypothesized that the transient mutators are those cells that are induced for the SOS response (Foster 1998). Recent results can be incorporated by further hypothesizing that in this minority population of SOS-induced cells, pol IV, and perhaps pol V, are present at high enough levels that the errors they make saturate the already low level of mismatch repair 
activity. In support of the role of pol IV, our preliminary results show that in a $\operatorname{din} B$ mutant population, $\mathrm{Lac}^{+}$adaptive revertants have the same low frequency of motility defects as do $\mathrm{Lac}^{-}$cells (S.L. Leugers and P.L. Foster, unpubl.).

It should be remembered that all of the conclusions about mutators and nonmutators depend on some very small numbers. Perhaps the weakest of these numbers is the frequency of nonselected mutations among the cells that do not have a selected mutation. In the $\mathrm{Lac}^{-}$ population, nonselected mutations can be detected on the episome during lactose selection (Foster 1997; Godoy et al. 2000), but their frequency on the chromosome is much lower, except when the cells are defective for mismatch repair.

\section{CONCLUSIONS}

Adaptive mutation to $\mathrm{Lac}^{+}$in strain FC40 occurs by a recombination-dependent mechanism, and the genetic requirements are the same as those for double-strand break repair. In addition to requiring the presence of lactose, the high rate of adaptive $\mathrm{Lac}^{+}$mutation also requires that the lac allele be on the episome and that conjugal functions be expressed in cis. Although other hypotheses have been advanced (Andersson et al. 1998), all of the facts are accommodated in the model presented in Figure 1. The important points of the model are that adaptive mutations are due to errors made during DNA synthesis initiated by recombination, that the recombination is initiated to repair the replication fork after it encounters the nick at the episome's conjugal origin, and that pol II, pol IV, and presumably pol V help to reassemble the replication fork. A similar sequence of events appears to occur in Saccharomyces cerevisiae after a doublestrand break; during recombinational repair of the break, mutations occur in nearby genes, at

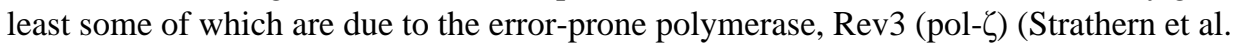
1995; Holbeck and Strathern 1997).

FC40 is ideally constructed to reveal this pathway of mutagenesis. One of the control elements that regulates expression of the tra operon is mutant on the version of the $\mathrm{F}$ episome found in laboratory strains of $E$. coli; thus, conjugal functions are partially constitutive (for review, see Rosche and Foster 2000). This probably accounts for the persistence of the nick at oriT. During nonlethal selection, when normal replication and its associate errors are minimal, the recombination pathway for mutation becomes dominant. However, whenever the replication fork encounters a problem, a similar sequence of events is predicted to occur. Thus, even in exponentially growing cells, some component of spontaneous mutations may be due to this recombination pathway. In addition, a growing body of evidence suggests that recombination may always be accompanied by DNA synthesis, and at least some of this synthesis may be error-prone.

Almost divorced from the production of most of the adaptive $\mathrm{Lac}^{+}$mutations during selection, mutations also occur in a subpopulation of cells that have a transient mutator phenotype. We still do not know if this is an induced response to stress or simply a pathological result of starvation. Our evidence suggests that the transient mutator state is due a combination of depleted methyl-directed mismatch repair and the induction of the SOS genes pol IV and, presumably, pol V. If this is correct, then pol IV and pol V may indeed be inducible mutases (Radman 1999). The transient mutators account for only a minority of single mutations, but for the vast majority of double or more mutants. Thus, their evolutionary importance may be slight when cells are presented with a challenge that is easily overcome, but all important when the solution to the problem calls for two or more simultaneous genetic changes. This may be the challenge presented to a potential cancer cell. 


\section{Acknowledgments}

I thank John Cairns for many years of collaboration, and for critically reading this article. I also thank the present and past members of my laboratory, and the many colleagues who have contributed to the intellectual development of this field. Work in my laboratory was supported by grant MCB 97838315 from the National Science Foundation.

\section{References}

Andersson DI, Slechta ES, Roth JR. Evidence that gene amplification underlies adaptive mutability of the bacterial lac operon. Science 1998;282:1133. [PubMed: 9804552]

Bates H, Randall SK, Rayssiguier C, Bridges BA, Goodman MF, Radman M. Spontaneous and UVinduced mutations in Escherichia coli K-12 strains with altered or absent DNA polymerase I. J Bacteriol 1989;171:2480. [PubMed: 2651403]

Boe L. Mechanism for induction of adaptive mutations in Escherichia coli. Mol Microbiol 1990;4:597. [PubMed: 2191182]

Bull HJ, McKenzie GJ, Hastings PJ, Rosenberg SM. Evidence that stationary-phase hypermutation in the Escherichia coli chromosome is promoted by recombination. Genetics 2000;154:1427. [PubMed: 10747042]

Cairns J. Mutation and cancer: The antecedents to our studies of adaptive mutation. Genetics 1998;148:1433. [PubMed: 9560363]

Cairns J. Appendix to The role of transient hypermutators in adaptive mutation in Escherichia coli. Proc Natl Acad Sci 1999;96:6866.

Cairns J, Foster PL. Adaptive reversion of a frameshift mutation in Escherichia coli. Genetics 1991;128:695. [PubMed: 1916241]

Cairns J, Overbaugh J, Miller S. The origin of mutants. Nature 1988;335:142. [PubMed: 3045565]

Calos MP, Miller JH. Genetic and sequence analysis of frameshift mutations induced by ICR-191. J Mol Biol 1981;153:39. [PubMed: 7040679]

Carter JR, Porter RD. traY and traI are required for oriT-dependent enhanced recombination between lac-containing plasmids and lambda plac5. J Bacteriol 1991;173:1027. [PubMed: 1846851]

Carter JR, Patel DR, Porter RD. The role of oriT in tra-dependent enhanced recombination between miniF-lacoriT and lambda plac5. Genet Res 1992;59:157. [PubMed: 1511865]

Chaudhury AM, Smith GR. Role of Escherichia coli RecBC enzyme in SOS induction. Mol Gen Genet 1985;201:525. [PubMed: 3911029]

Cox MM, Goodman MF, Kreuzer KN, Sherratt DJ, Sandler SJ, Marians KJ. The importance of repairing stalled replication forks. Nature 2000;404:37. [PubMed: 10716434]

Escarceller M, Hicks J, Gudmundsson G, Trump G, Touati D, Lovett S, Foster PL, McEntee K, Goodman MF. Involvement of Escherichia coli DNA polymerase II in response to oxidative damage and adaptive mutation. J Bacteriol 1994;176:6221. [PubMed: 7928992]

Feng G, Tsui HCT, Winkler ME. Depletion of the cellular amounts of the MutS and MutH methyl-directed mismatch repair proteins in stationary-phase Escherichia coli K-12 cells. J Bacteriol 1996;178:2388. [PubMed: 8636043]

Fijalkowska IJ, Schaaper RM. Antimutator mutations in the $\alpha$ subunit of Escherichia coli DNA polymerase III: Identification of the responsible mutations and alignment with other DNA polymerases. Genetics 1993;134:1039. [PubMed: 8375647]

Firth, N.; Ippen-Ihler, K.; Skurray, RA. Structure and function of the F factor and mechanism of conjugation. In: Neidhardt, FC., et al., editors. Escherichia coli and Salmonella: Cellular and molecular biology. American Society for Microbiology; Washington, D.C: 1996. p. 2377

Foster PL. Adaptive mutation: The uses of adversity. Annu Rev Microbiol 1993;47:467. [PubMed: 8257106]

Foster PL. Population dynamics of a $\mathrm{Lac}^{-}$strain of Escherichia coli during selection for lactose utilization. Genetics 1994;138:253. [PubMed: 7828809]

Foster PL. Nonadaptive mutations occur on the $\mathrm{F}^{\prime}$ episome during adaptive mutation conditions in Escherichia coli. J Bacteriol 1997;179:1550. [PubMed: 9045812]

Foster PL. Adaptive mutation: Has the unicorn landed? Genetics 1998;148:1453. [PubMed: 9560365] 
Foster PL. Are adaptive mutations due to a decline in mismatch repair? The evidence is lacking. Mutat Res 1999a;436:179. [PubMed: 10095139]

Foster PL. Mechanisms of stationary phase mutation: A decade of adaptive mutation. Annu Rev Genet 1999b;33:57. [PubMed: 10690404]

Foster PL, Cairns J. Mechanisms of directed mutation. Genetics 1992;131:783. [PubMed: 1516815]

Foster PL, Rosche WA. Increased episomal replication accounts for the high rate of adaptive mutation in recD mutants of Escherichia coli. Genetics 1999;152:15. [PubMed: 10224241]

Foster PL, Trimarchi JM. Adaptive reversion of a frameshift mutation in Escherichia coli by simple base deletions in homopolymeric runs. Science 1994;265:407. [PubMed: 8023164]

Foster PL, Trimarchi JM. Adaptive reversion of an episomal frameshift mutation in Escherichia coli requires conjugal functions but not actual conjugation. Proc Natl Acad Sci 1995a;92:5487. [PubMed: 7777535]

Foster PL, Trimarchi JM. Conjugation is not required for adaptive reversion of an episomal frameshift mutation in Escherichia coli. J Bacteriol 1995b;177:6670. [PubMed: 7592449]

Foster PL, Trimarchi JM, Maurer RA. Two enzymes, both of which process recombination intermediates, have opposite effects on adaptive mutation in Escherichia coli. Genetics 1996;142:25. [PubMed: 8770582]

Foster PL, Gudmundsson G, Trimarchi JM, Cai H, Goodman MF. Proofreading-defective DNA polymerase II increases adaptive mutation in Escherichia coli. Proc Natl Acad Sci 1995;92:7951. [PubMed: 7644519]

Frost LS, Manchak J. $\mathrm{F}^{-}$phenocopies: Characterization of expression of the $\mathrm{F}$ transfer region in stationary phase. Microbiology 1998;144:2579. [PubMed: 9782507]

Galitski T, Roth JR. Evidence that F plasmid transfer replication underlies apparent adaptive mutation. Science 1995;268:421. [PubMed: 7716546]

Godoy VG, Gizatullin FS, Fox MS. Some features of the mutability of bacteria during nonlethal selection. Genetics 2000;154:49. [PubMed: 10628968]

Goodman MF. Coping with replication 'train wrecks' in Escherichia coli using Pol V, Pol II and RecA proteins. Trends Biochem Sci 2000;25:189. [PubMed: 10754553]

Hall BG. Spontaneous point mutations that occur more often when they are advantageous than when they are neutral. Genetics 1990;126:5. [PubMed: 2227388]

Harris RS, Bull HJ, Rosenberg SM. A direct role for DNA polymerase III in adaptive reversion of a frameshift mutation in Escherichia coli. Mutat Res 1997;375:19. [PubMed: 9129676]

Harris RS, Longerich S, Rosenberg SM. Recombination in adaptive mutation. Science 1994;264:258. [PubMed: 8146657]

Harris RS, Ross KJ, Rosenberg SM. Opposing roles of the Holliday junction processing systems of Escherichia coli in recombination-dependent adaptive mutation. Genetics 1996;142:681. [PubMed: 8849879]

Holbeck SL, Strathern JN. A role for REV3 in mutagenesis during double-strand break repair in Saccharomyces cerevisiae. Genetics 1997;147:1017. [PubMed: 9383049]

Kim SR, Maenhaut-Michel G, Yamada M, Yamamoto Y, Matsui K, Sofuni T, Nohmi T, Ohmori H. Multiple pathways for SOS-induced mutagenesis in Escherichia coli: An overexpression of dinB/ $\operatorname{din} P$ results in strongly enhancing mutagenesis in the absence of any exogenous treatment to damage DNA. Proc Natl Acad Sci 1997;94:13792. [PubMed: 9391106]

Kogoma T. Is RecF a DNA replication protein? Proc Natl Acad Sci 1997a;94:3483. [PubMed: 9108000]

Kogoma T. Stable DNA replication: Interplay between DNA replication, homologous recombination, and transcription. Microbiol Mol Biol Rev 1997b;61:212. [PubMed: 9184011]

Kogoma T, Cadwell GW, Barnard KG, Asai T. The DNA replication priming protein, PriA, is required for homologous recombination and double-strand break repair. J Bacteriol 1996;178:1258. [PubMed: 8631700]

Kowalczykowski SD. Initiation of genetic recombination and recombination-dependent replication. Trends Biochem Sci 2000;25:156. [PubMed: 10754547]

Kuzminov A. Collapse and repair of replication forks in Escherichia coli. Mol Microbiol 1995;16:373. [PubMed: 7565099] 
Kuzminov A. Recombinational repair of DNA damage in Escherichia coli and bacteriophage $\lambda$. Microbiol Mol Biol Rev 1999;63:751. [PubMed: 10585965]

Kuzminov A, Stahl FW. Double-strand end repair via the RecBC pathway in Escherichia coli primes DNA replication. Genes Dev 1999;13:345. [PubMed: 9990858]

Lloyd RG, Buckman C. Genetic analysis of the recG locus of Escherichia coli K12 and of its role in recombination and DNA repair. J Bacteriol 1991;173:1004. [PubMed: 1846849]

Luria SE, Delbrück M. Mutations of bacteria from virus sensitivity to virus resistance. Genetics 1943;28:491. [PubMed: 17247100]

Lwoff A. Some problems connected with spontaneous biochemical mutations in bacteria. Cold Spring Harbor Symp Quant Biol 1946;11:139.

Mandal TN, Mahdi AA, Sharples GJ, Lloyd RG. Resolution of Holliday intermediates in recombination and DNA repair: Indirect suppression of $r u v A, r u v B$, and $r u v C$ mutations. J Bacteriol 1993;175:4325. [PubMed: 8331065]

McGlynn P, Lloyd RG. Modulation of RNA polymerase by (p)ppGpp reveals a RecG-dependent mechanism for replication fork progression. Cell 2000;101:35. [PubMed: 10778854]

McKenzie GJ, Harris RS, Lee PL, Rosenberg SM. The SOS response regulates adaptive mutation. Proc Natl Acad Sci 2000;97:6646. [PubMed: 10829077]

Miller JH. Mutagenic specificity of ultraviolet light. J Mol Biol 1985;182:45. [PubMed: 3923204]

Modrich P, Lahue R. Mismatch repair in replication fidelity, genetic recombination, and cancer biology. Annu Rev Biochem 1996;65:101. [PubMed: 8811176]

Mosig G. Recombination and recombination-dependent DNA replication in bacteriophage T4. Annu Rev Genet 1998;32:379. [PubMed: 9928485]

Müller-Hill B, Kania J. Lac repressor can be fused to $\beta$-galactosidase. Nature 1974;249:561. [PubMed: 4599764]

Ninio J. Transient mutators: A semiquantitative analysis of the influence of translation and transcription errors on mutation rates. Genetics 1991;129:957. [PubMed: 1752431]

Radicella JP, Park PU, Fox MS. Adaptive mutation in Escherichia coli: A role for conjugation. Science 1995;268:418. [PubMed: 7716545]

Radman M. Enzymes of evolutionary change. Nature 1999;401:866. [PubMed: 10553899]

Rangarajan S, Woodgate R, Goodman MF. A phenotype for enigmatic DNA polymerase II: A pivotal role for Pol II in replication restart in UV-irradiated Escherichia coli. Proc Natl Acad Sci 2000;96:9224. [PubMed: 10430924]

Reddy M, Gowrishankar J. A genetic strategy to demonstrate the occurrence of spontaneous mutations in non-dividing cells within colonies of Escherichia coli. Genetics 1997;147:991. [PubMed: 9383047]

Rinken R, Thoms B, Wackernagel W. Evidence that $r e c B C$-dependent degradation of duplex DNA in Escherichia coli recD mutants involves DNA unwinding. J Bacteriol 1992;174:5424. [PubMed: 1322885]

Rosche WA, Foster PL. The role of transient hypermutators in adaptive mutation in Escherichia coli. Proc Natl Acad Sci 1999;96:6862. [PubMed: 10359804]

Rosche, WA.; Foster, PL. Mutation under stress: Adaptive mutation in Escherichia coli. In: Storz, G.; Hengge-Aronis, R., editors. Bacterial stress responses. ASM Press; Washington, D.C: 2000. p. 239

Rosenberg SM, Longerich S, Gee P, Harris RS. Adaptive mutation by deletions in small mononucleotide repeats. Science 1994;265:405. [PubMed: 8023163]

Ryan FJ. Spontaneous mutation in non-dividing bacteria. Genetics 1955;40:726. [PubMed: 17247585]

Ryan FJ, Nakada D, Schneider MJ. Is DNA replication a necessary condition for spontaneous mutation? Z Vererbungsl 1961;92:38. [PubMed: 13744985]

Sandler SJ, Samra HS, Clark AJ. Differential suppression of priA2::kan phenotypes in Escherichia coli K-12 by mutations in priA, lexA, and dnaC. Genetics 1996;143:5. [PubMed: 8722757]

Seifert HS, Porter RD. Enhanced recombination between lambda plac5 and F42lac: Identification of cis- and trans-acting factors. Proc Natl Acad Sci 1984;81:7500. [PubMed: 6095300]

Seigneur M, Bidnenko V, Ehrlich SD, Michel B. RuvAB acts at arrested replication forks. Cell 1998;95:419. [PubMed: 9814711] 
Shapiro JA. Observations on the formation of clones containing araB-lacZ cistron fusions. Mol Gen Genet 1984;194:79. [PubMed: 6233472]

Stahl FW. A unicorn in the garden. Nature 1988;335:112. [PubMed: 3412467]

Strathern JN, Shafer BK, McGill CB. DNA synthesis errors associated with double-strand-break repair. Genetics 1995;140:965. [PubMed: 7672595]

Tang M, Shen X, Frank EG, O'Donnell M, Woodgate R, Goodman MF. UmuD' (2)C is an error-prone DNA polymerase, Escherichia coli Pol V. Proc Natl Acad Sci 1999;96:8919. [PubMed: 10430871]

Tang M, Pham P, Shen X, Taylor JS, O’Donnell M, Woodgate R, Goodman MF. Roles of E. coli DNA polymerase IV and V in lesion-targeted and untargeted SOS mutagenesis. Nature 2000;404:1014. [PubMed: 10801133]

Torkelson J, Harris RS, Lombardo MJ, Nagendran J, Thulin C, Rosenberg SM. Genome-wide hypermutation in a subpopulation of stationary-phase cells underlies recombination-dependent adaptive mutation. EMBO J 1997;16:3303. [PubMed: 9214645]

Wagner J, Gruz P, Kim SR, Yamada M, Matsui K, Fuchs RPP, Nohmi T. The dinB gene encodes a novel E. coli DNA polymerase, DNA pol IV, involved in mutagenesis. Mol Cell 1999;4:281. [PubMed: 10488344]

Whitby MC, Lloyd RG. Branch migration of three-strand recombination intermediates by RecG, a possible pathway for securing exchanges initiated by 3'-tailed duplex DNA. EMBO J 1995;14:3302. [PubMed: 7628432]

Whitby MC, Ryder L, Lloyd RG. Reverse branch migration of Holliday junctions by RecG protein: A new mechanism for resolution of intermediates in recombination and DNA repair. Cell 1993;75:341. [PubMed: 8402917] 

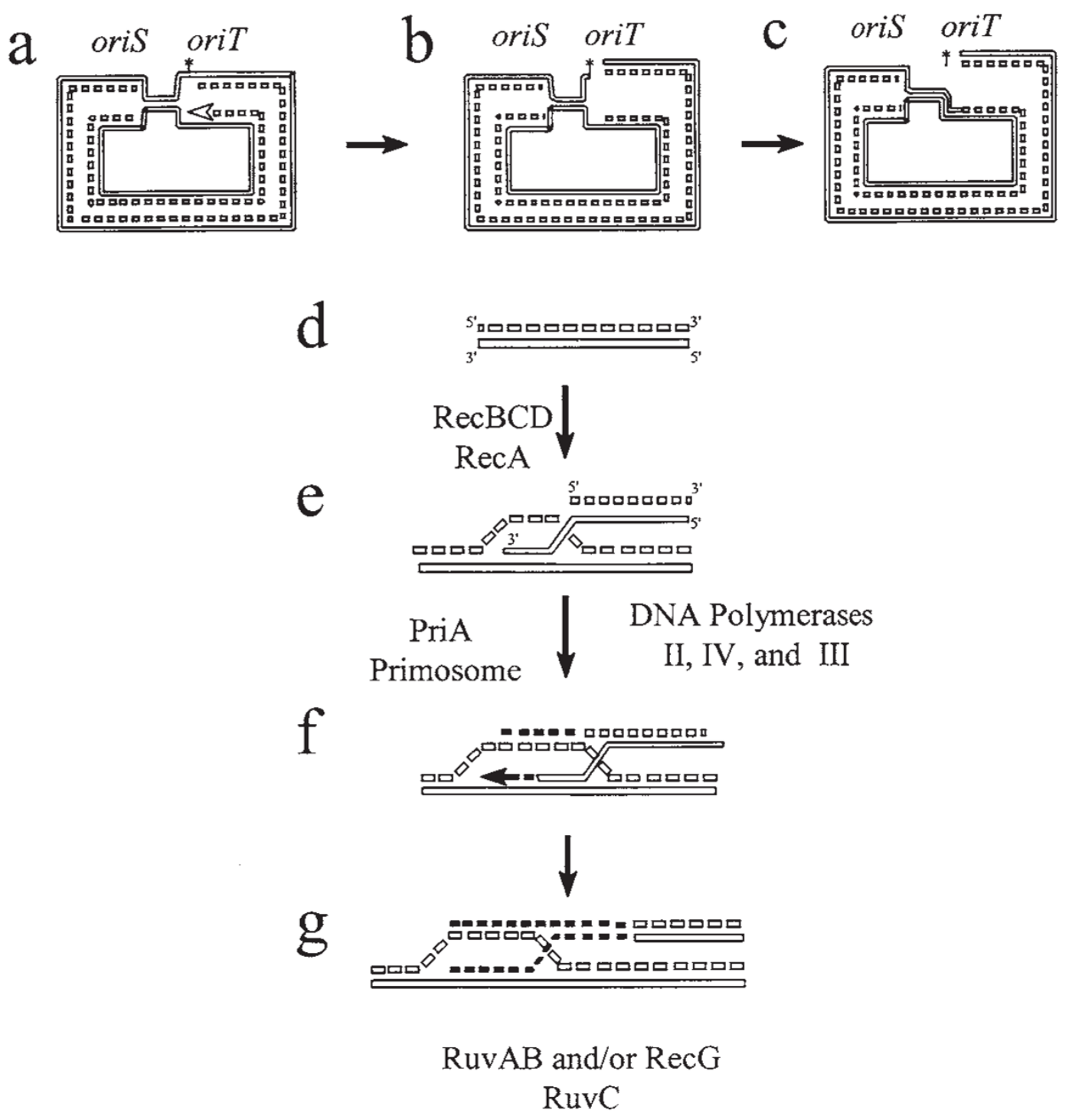

Figure 1.

A model for recombination-dependent mutation. $(a-c)$ Collapse of the replication fork at oriT; $(d-e)$ RecABCD-catalyzed invasion of the broken arm into the homologous sister chromosome; $(f)$ establishment of the four-stranded Holliday junction and restoration of the replication fork; $(g)$ translocation of the Holliday junction by RuvAB and/or RecG. Resolution of the Holliday junction by RuvC is not shown (see text for details). (Dashed lines) Newly synthesized DNA; (filled dashed lines) DNA synthesized during recombination. The arrowhead indicates the $3^{\prime}$ end of the leading DNA strand; the asterisk at oriT indicates TraI. For clarity, the invading strands have been abbreviated and flipped vertically between panels $b$ and $c$. 


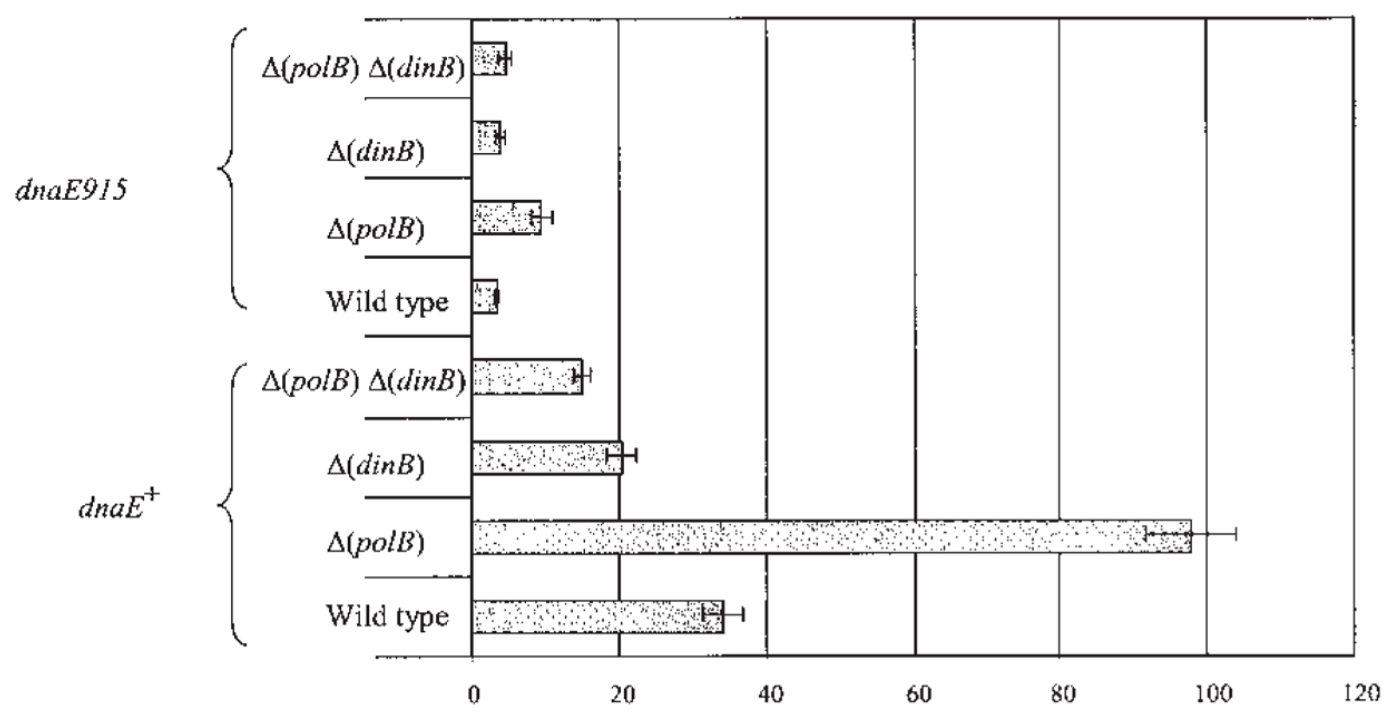

Lac ${ }^{+}$per Day, Days 3 to 5

Figure 2.

Effects of DNA polymerase II, III, and IV on adaptive $\mathrm{Lac}^{+}$mutation in E. coli strain FC40. Values are the mean $( \pm \mathrm{SEM})$ number of $\mathrm{Lac}^{+}$mutants appearing days $3-5$ after plating. Several experiments have been combined, and each value represents from 12 to 23 determinations using our small-scale assay described in Foster et al. (1996). 


\section{Table 1}

Genetic Characteristics for Adaptive Mutation in E. coli Strain FC40

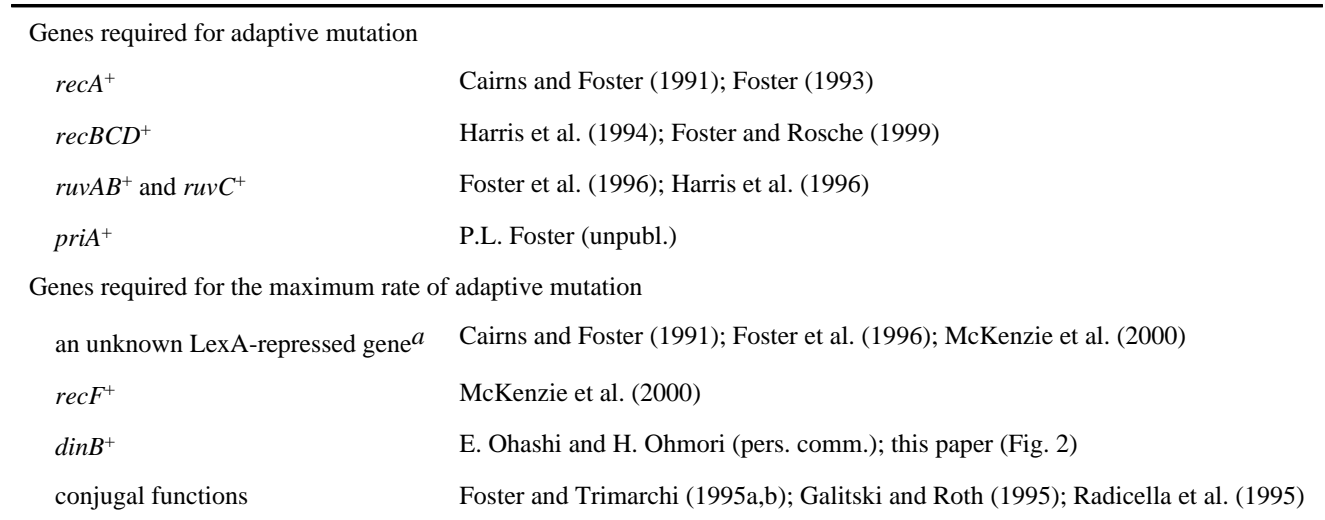

Defects that greatly enhance adaptive mutation

\begin{tabular}{ll}
$r e c D^{-}$ & Harris et al. (1994); Foster and Rosche (1999) \\
$r e c G^{-}$ & Foster et al. (1996); Harris et al. (1996) \\
polA1 & P.L. Foster (unpubl.) \\
\hline
\end{tabular}

${ }^{a}$ This is probably not $r u v A B$ (P.L. Foster, unpubl.) but could be $\operatorname{din} B$. See text and Figure 2. 
Table 2

DNA Polymerases in Escherichia coli

\begin{tabular}{|c|c|c|c|c|}
\hline & Function & Gene & Accuracy & Processivity \\
\hline \multicolumn{5}{|c|}{ Housekeeping polymerases } \\
\hline pol III $(\alpha)$ & replication & dnaE & accurate & processive \\
\hline pol I & DNA repair & polA & accurate & processive \\
\hline \multicolumn{5}{|c|}{ DNA-damage inducible polymerases } \\
\hline pol II & DNA repair & polB/dinA & accurate & processive \\
\hline pol IV & mutagenesis & $\operatorname{din} B$ & error-prone & distributive \\
\hline pol V & mutagenesis & uтиDC & error-prone & distributive \\
\hline
\end{tabular}

